\title{
Template for using biological trait groupings when exploring large-scale variation in seafloor multifunctionality
}

\author{
Villnäs, Anna Pia Maria \\ 2018-01
}

Villnäs , A P M , Hewitt , J , Snickars , M , Westerbom , M \& Norkko , A M 2018 , ' Template for using biological trait groupings when exploring large-scale variation in seafloor

multifunctionality ' , Ecological Applications , vol. 28 , no. 1 , 28(1) , pp. 78-94 . https://doi.org/10.1002/eap.1630

http://hdl.handle.net/10138/234587

https://doi.org/10.1002/eap.1630

publishedVersion

Downloaded from Helda, University of Helsinki institutional repository.

This is an electronic reprint of the original article.

This reprint may differ from the original in pagination and typographic detail.

Please cite the original version. 


\title{
Template for using biological trait groupings when exploring large-scale variation in seafloor multifunctionality
}

\author{
Anna Villnäs, ${ }^{1,6}$ Judi Hewitt, ${ }^{2}$ Martin Snickars, ${ }^{3}$ Mats Westerbom, ${ }^{1,4}$ and Alf Norkko ${ }^{1,5}$ \\ ${ }^{1}$ Tvärminne Zoological Station, University of Helsinki, J.A. Palménin tie 260, FI-10900 Hanko, Finland \\ ${ }^{2}$ Marine Ecology Department Hamilton, National Institute of Water and Atmospheric Research, Hamilton 3251 New Zealand \\ ${ }^{3}$ Department of Biosciences, Environmental and Marine Biology, Ảbo Akademi University, FI-20520 Turku, Finland \\ ${ }^{4}$ Metsähallitus, Parks \& Wildlife Finland, PO Box 94, FI-01301 Vantaa, Finland \\ ${ }^{5}$ Baltic Sea Centre, Stockholm University, SE-106 91 Stockholm, Sweden
}

\begin{abstract}
Understanding large-scale spatial variation in ecosystem properties and associated functionality is key for successful conservation of ecosystems. This study provides a template for how to estimate differences in ecosystem functionality over large spatial scales by using groupings of biological traits. We focus on trait groupings that describe three important benthic ecosystem properties, namely bioturbation, community stability, and juvenile dispersal. Recognizing that groups of traits interact and are constrained within an organism, we statistically define important functional trait subgroups that describe each ecosystem property. The sub-groups are scored according to their weighted ecological impact to gain an overall estimation of the cumulative expression of each ecosystem property at individual sites. Furthermore, by assigning each property a value relative to its observed maximum, and by summing up the individual property values, we offer an estimate of benthic ecosystem multifunctionality. Based on a spatially extensive benthic data set, we were able to identify coastal areas with high and low potential for the considered benthic ecosystem properties and the measure of ecosystem multifunctionality. Importantly, we show that a large part of the spatial variation in functional trait sub-groups and in benthic ecosystem multifunctionality was explained by environmental change. Our results indicate that through this simplification it is possible to estimate the functionality of the seafloor. Such information is vital in marine spatial planning efforts striving to balance the utilization with the preservation of natural resources.
\end{abstract}

Key words: Baltic Sea; benthic communities; ecosystem multifunctionality; groupings of biological traits; marine spatial planning; sediment ecosystem function; spatial distribution.

\section{INTRODUCTION}

A large part of the world's population lives beside the sea and relies on the essential goods and services that the marine ecosystems provide. Simultaneously, human activities are increasingly disturbing coastal environments (Halpern et al. 2008), resulting in habitat alterations and degrading biodiversity (Lotze et al. 2006). This undermines species' contribution to important ecosystem functions. Ecosystem functions underlie the properties, goods and services of an ecosystem, with ecosystem properties representing pools of materials and process rates, and also ecosystem stability and resilience (Hooper et al. 2005). Efforts are being made to preserve the functionality of coastal ecosystems by implementing ecosystembased management through marine spatial planning (MSP; Foley et al. 2010). An effective MSP should be based on information regarding the spatial dynamics of biodiversity and ecosystem properties, which ensures that the desired ecosystem functions are, in fact, provided (Foley et al. 2010, Böhnke-Henrichs et al. 2013).

Manuscript received 9 March 2017; revised 28 June 2017; accepted 3 August 2017. Corresponding Editor: Éva E. Plaganyi.

${ }^{6}$ E-mail: anna.villnas@helsinki.fi
Spatial data on biodiversity and associated ecosystem functions is often scarce in marine systems, due to logistical difficulties with obtaining data and financial constraints. Hence evaluations of biodiversity-ecosystem function relationships are often performed over small spatial scales (Snelgrove et al. 2014), but see, e.g., Lohrer et al. (2015) for an example on how field data can be used to upscale ecosystem functions across time and space. Still, as marine ecosystems often span habitats and environmental and anthropogenic gradients, the extrapolation of local properties onto larger scales is complicated, undermining our ability to assess real-world contributions of biodiversity to ecosystem function (Snelgrove et al. 2014). Functional biogeography, i.e., the examination of patterns, causes, and consequences of the spatial variation in biological trait diversity, could bridge the gap between biodiversity patterns and ecosystems functions over larger scales (Violle et al. 2014).

Biological traits are the morphological, physiological, phenological or behavioral features of an organism that describe its performance (Violle et al. 2014). Traits are often used as surrogates for ecosystem properties as they have been documented to affect multiple ecosystem functions, such as nutrient cycling (Norkko et al. 2013), primary (Lohrer et al. 2015) and secondary production 
(Bolam and Eggleton 2014), and sediment erodibility (Harris et al. 2015). The trait expression of differing taxonomic communities is found to be rather consistent over large geographic scales, as a result of environmental filtering (Poff 1997, Statzner et al. 2001, Bremner et al. 2006, Hewitt et al. 2008, Tolonen et al. 2016). This consistency enables comparisons of ecological functions over larger areas, where differences in species composition could make traditional, species-based assessments difficult (Bremner et al. 2003). Importantly, biological traits are known to respond to environmental change (Lavorel et al. 2011) as well as anthropogenic disturbances (Villnäs et al. 2011, 2013, Mouillot et al. 2013). Biological traits can also highlight small-scale environmental heterogeneity (Bremner et al. 2003). While differences in functional expressions between habitats have been attributed to differences in organisms' densities, within-habitat differences can be due to presence/absence of individual traits (Hewitt et al. 2008).

To improve the predictive performance of trait-based approaches it is important to recognize that traits interact and are constrained within a species (Poff 1997, Pearson 2001, Verberk et al. 2013, Winemiller et al. 2015, Greenfield et al. 2016). Trait interactions occur if the possession of a certain modality inclines a species to express other specific features (Verberk et al. 2013). Interactions among traits are the result of the adaptive responses of species' to their prevailing environment as well as natural selection (Poff 1997, Pearson 2001, de Bello et al. 2010, Verberk et al. 2013). Although the theoretical number of random trait groupings can be potentially large, only a small subset of combinations might be present if the realized linkages among species' traits are accounted for. The use of trait groupings could be especially helpful when exploring spatial variation in ecosystem functioning, as they could enable the identification of trait modalities most important for the functions under consideration and improve the signal to noise ratio by avoiding the averaging effect (Verberk et al. 2013). The separation of overall trait composition into functional groups might thus increase the variation explained by local environmental drivers (Tolonen et al. 2016). An increasing number of recent studies are accounting for the way that trait modalities interact and are constrained within a species (e.g., Sirot et al. 2015, Greenfield et al. 2016, Tolonen et al. 2016).

The approach of considering combinations of biological attributes, in terms of functional groups, has a long history in marine benthic ecology (e.g., Fauchald and Jumars 1979, Bonsdorff and Pearson 1999, Pearson 2001). We argue that such groupings of biological traits could be particularly useful when assessing spatial variation in benthic ecosystem properties across habitats and environmental gradients. The Baltic Sea offers the perfect setting for exploring spatial variability in groupings of biological traits. The structural and functional biodiversity of the benthic communities in this estuarine area is naturally reduced due to the low salinity (Bonsdorff
2006, Villnäs and Norkko 2011), and the biological traits of the residing species are consequently quite well known. Furthermore, as the potential for functional redundancy might be lower here than in more diverse systems (Elmgren and Hill 1997), disturbances might have far-reaching consequences for ecosystem functionality. Although this brackish water body is continuously exposed to multiple stressors, including widespread eutrophication-induced hypoxia as a major threat to benthic ecosystems (Conley et al. 2011, Norkko et al. 2015), spatial variation in benthic ecosystem functions has rarely been considered in ecosystem based management or marine spatial planning in the Baltic Sea. The aim of this study is to offer a template for how to estimate large-scale spatial variation in benthic ecosystem properties by using groupings of biological traits. We (1) statistically confirm trait groupings in order to (2) examine large-scale spatial variation in important benthic ecosystem properties and (3) explore their response to environmental change. We account for the fact that each functional trait subgroup may have a unique contribution to the cumulative expression of an ecosystem property and acknowledge that species simultaneously affect multiple properties by illustrating the spatial pattern in benthic ecosystem multifunctionality.

We focus on three properties performed by the benthic community, i.e., bioturbation, community stability, and juvenile dispersal potential. These properties are key components of essential functions provided by coastal benthic ecosystems. Benthic bioturbation influences the cycling of organic matter, energy, and nutrients (Kristensen 2000). Specifically, size, environmental position, and reworking mode of the benthic fauna are essential traits that regulate biological sediment mixing, which directs sediment oxygen and redox gradients and ultimately the cycling of carbon and nutrients (Kristensen 2000, Solan et al. 2004, Queirós et al. 2013). Community stability and the potential for juvenile dispersal contributes to the stability and recovery potential of the benthic ecosystem when facing environmental change (Foley et al. 2010, Pilditch et al. 2015). Traits such as size and longevity represent the stability of a community, as the presence of large, long-lived species is indicative of a mature community (that has not been severely disturbed during a longer period; Pearson and Rosenberg 1978). Such species can also function as facilitators through improving living conditions and offering refugia for other species (Norkko et al. 2006, Thrush et al. 2006). Furthermore, changes in body size patterns are likely to affect predator-prey interactions, which determines food web stability (Emmerson and Raffaelli 2004). From a benthic ecosystem function perspective, dispersal, re-colonization, and connectivity are essential for maintaining biodiversity and the resilience of the ecosystem (Pilditch et al. 2015). Especially in shallow coastal and estuarine areas, where the benthic and pelagic realm are intimately linked, the considered properties are important for the functioning of the entire ecosystem 
(Kristensen et al. 2014, Griffiths et al. 2017). Still, even in open waters, the functions provided by the benthic communities have proven to be important from an ecosystem perspective (e.g., Norkko et al. 2015, Belley and Snelgrove 2016). Consequently, we argue that these properties are essential for sustaining ecosystem functions and services in disturbance-prone coastal areas, as exemplified in this study by focusing on the Baltic Sea.

\section{Methods}

The sampling area was located in the northern Baltic Sea, at the southwestern coast of Finland (Fig. 1). This non-tidal region is characterized by an irregular coastline and an extensive archipelago of thousands of islands. Soft-sediment benthic communities at 427 sites were sampled in August to September of 2012. Sampling sites were selected by random stratification, using modeled depth, wave exposure, salinity, and turbidity. Generally, sites were situated within a depth range of 0.5-25 m (Appendix S1: Table S1). GPS coordinates (decimal degrees) and depth were measured at all sites at the time of sampling. The samples cover a large area encompassing four different water types (separated according to the typology of the EU Water Framework Directive on the basis of salinity, location, duration of ice coverage, substratum composition, and wave exposure [Vuori et al. 2006]). The four water types describe a complex archipelago and are further divided into 17 different water basins (Karonen et al. 2015), according to hydro-morphological, biological, and physicochemical differences (Fig. 1).
Benthic macrofauna was collected with one replicate sample at each site. At 335 sites, a Petite Ponar grab sampler $\left(231 \mathrm{~cm}^{2}\right)$ was used, while 92 additional sites were sampled by a Peterson grab $\left(450 \mathrm{~cm}^{2}\right)$. Individual counts were converted to density (individuals $/ \mathrm{m}^{2}$ ), and statistical analyses confirmed that no differences between the two sampling methods occurred (ANOSIM global $R=-0.07$, $P=0.97$ ). Samples were sieved using a $0.5 \mathrm{~mm}$ mesh and preserved in $70 \%$ ethanol. Species were sorted and enumerated to the lowest practical level using a binocular microscope. The benthic fauna was dominated by the bivalve Macoma balthica, gastropods belonging to Hydrobiidae, the polychate complex Marenzelleria spp., as well as species belonging to Chironomidae. Meiofauna (Turbellaria, Nematoda, Ostracoda, and Oligochaeta), pelagic (Mysidaceae, Palaemon elegans, Hydracarina), and parasitic species (Helobdella stagnalis, Piscicola spp.) were excluded from the data set. Wave exposure was modelled for all the sites in the data set (Bekkby et al. 2008).

For a more rigorous analysis of the relationships between trait groupings and environmental variables, a subset of 72 sites sampled in 2012 were revisited in the summer of 2013, when additional environmental variables were measured (Fig. 1; Valanko \& Kauppi). The sediment was sampled with an Ekman grab and analyzed for organic matter (LOI) and sediment grain size (gravel, $2 \mathrm{~mm}$; very coarse sand, $1 \mathrm{~mm}$; coarse sand, $0.5 \mathrm{~mm}$; fine sand, $0.25 \mathrm{~mm}$; very fine sand, $>0.063 \mathrm{~mm}$; and mud, $<0.063 \mathrm{~mm}$ ). Depth, bottom, and surface water salinity and temperature were measured with a conductivity, temperature and depth probe, while bottom water oxygen concentration $(\mathrm{mg} / \mathrm{L}, \%)$ was determined with the Winkler procedure. Water

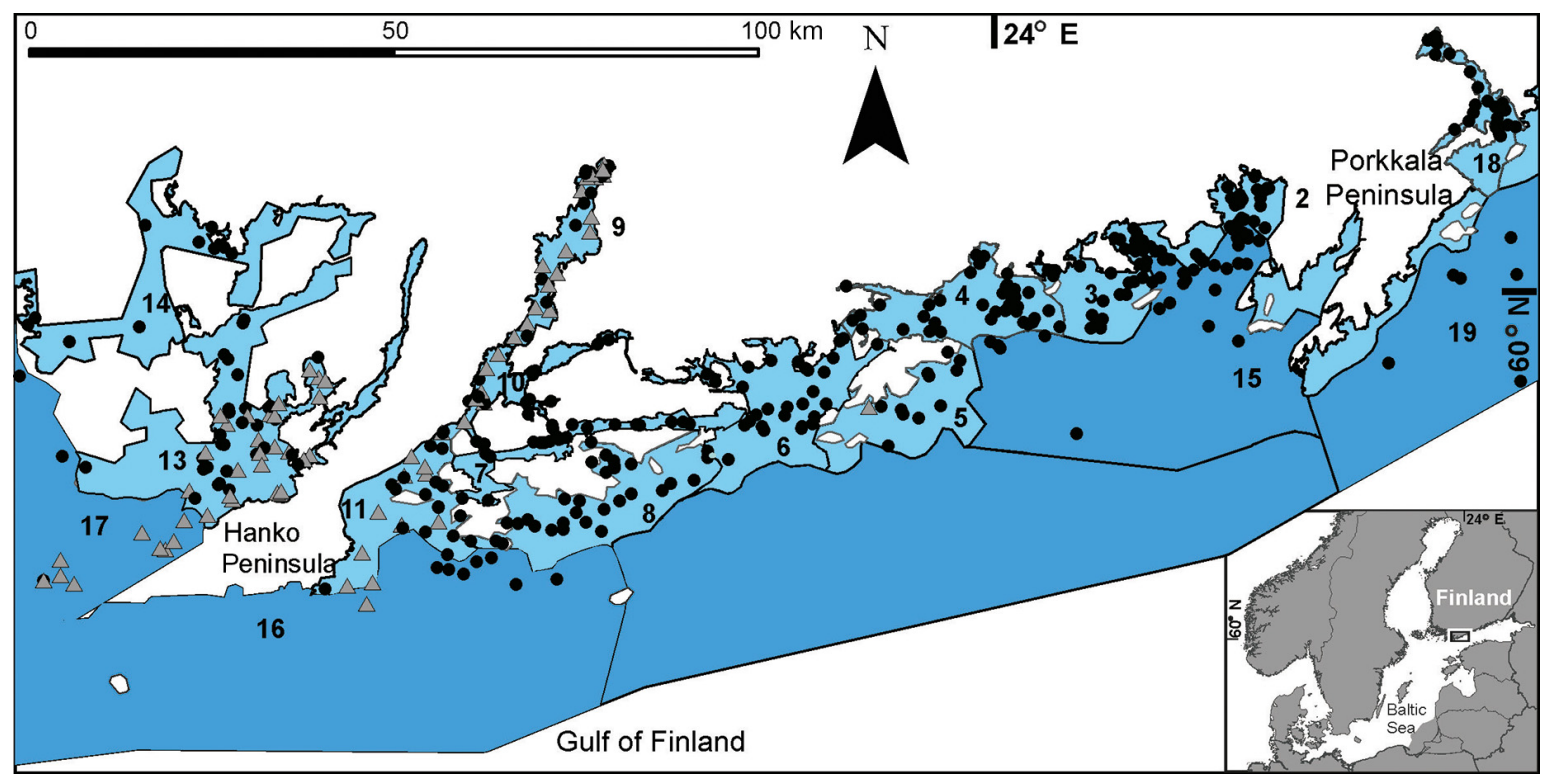

FIG. 1. The different water basins considered in this study are outlined; for basin numbers and corresponding names see Appendix S3: Table S1. The water basins represent the following water types; the inner (light blue) and outer (dark blue) archipelago areas of the Gulf of Finland and the southwestern Finnish archipelago. Circles mark the sites sampled in 2012 while triangles mark the subset of sites revisited in 2013 for quantification of environmental variables. [Color figure can be viewed at wileyonlinelibrary.com] 
transparency (Secchi depth) was assessed with a Secchi disk. Importantly, the subset of sites represented the variability in environmental and benthic parameters of the extended data set (Appendix S1: Table S1).

\section{Groupings of benthic trait modalities}

Proxies of three benthic properties, i.e., the bioturbation potential, the stability of the community and the potential for larval dispersal, were investigated by using expert definition of the biological traits contributing to the expression of each property. In total, seven traits and 26 different trait modalities were considered (Table 1). Species were assigned to these trait modalities using published classifications as well as taxonomic and morphologic sources of information (e.g., Fish and Fish 1996, MarLIN 2006, Valanko et al. 2010, Törnroos and Bonsdorff 2012). To account for the multiple modalities

TABLE 1. Traits and trait modalities selected to represent the considered benthic ecosystem properties (EP) and functions (EF).

\begin{tabular}{|c|c|}
\hline Ecosystem function, ecosystem property, trait groups, trait modalities & Explanation \\
\hline \multicolumn{2}{|l|}{ Nutrient cycling, bioremediation of waste, sediment stability } \\
\hline \multicolumn{2}{|l|}{ Bioturbation potential } \\
\hline \multicolumn{2}{|l|}{ Sediment reworking mode } \\
\hline \multicolumn{2}{|l|}{ No transport } \\
\hline Surficial modifier & modifies the sediment surface \\
\hline Tube-dweller & builds and dwells in a tube \\
\hline Bio diffuser & moves particles in random manner over short distances \\
\hline Gallery diffuser & $\begin{array}{l}\text { excavates burrows, particles moved by biodiffusion } \\
\text { or directly }\end{array}$ \\
\hline \multicolumn{2}{|l|}{ Environmental position } \\
\hline Infauna top & in the uppermost $2 \mathrm{~cm}$ of the sediment \\
\hline Infauna bottom & in deeper layers of the sediment $(2-5 \mathrm{~cm})$ \\
\hline Pelagic & in the water column \\
\hline Epibenthic & on the sediment surface \\
\hline \multicolumn{2}{|l|}{ Maximum size } \\
\hline Very small & $<0.001 \mathrm{~g}$ \\
\hline Small & $0.001-0.01 \mathrm{~g}$ \\
\hline Medium & $0.01-0.1 \mathrm{~g}$ \\
\hline Large & $0.1-1.0 \mathrm{~g}$ \\
\hline \multicolumn{2}{|l|}{ Resilience } \\
\hline \multicolumn{2}{|l|}{ Stability } \\
\hline \multicolumn{2}{|l|}{ Longevity } \\
\hline \multicolumn{2}{|l|}{$<1 \mathrm{yr}$} \\
\hline \multicolumn{2}{|l|}{$1-2 \mathrm{yr}$} \\
\hline \multicolumn{2}{|l|}{$2-5 \mathrm{yr}$} \\
\hline \multicolumn{2}{|l|}{$5-10 \mathrm{yr}$} \\
\hline \multicolumn{2}{|l|}{ Maximum size } \\
\hline Very small & $<0.001 \mathrm{~g}$ \\
\hline Small & $0.001-0.01 \mathrm{~g}$ \\
\hline Medium & $0.01-0.1 \mathrm{~g}$ \\
\hline Large & $0.1-1.0 \mathrm{~g}$ \\
\hline \multicolumn{2}{|l|}{ Dispersal, recovery, resilience } \\
\hline \multicolumn{2}{|l|}{ Potential for juvenile dispersal } \\
\hline \multicolumn{2}{|l|}{ Reproductive frequency } \\
\hline Semelparous & breeds only once, then dies \\
\hline Annual episodic & breeds every year in discrete periods \\
\hline Annual protracted & breeds every year during an extended period \\
\hline \multicolumn{2}{|l|}{ Larval type } \\
\hline Direct development & development without a larval stage \\
\hline Lecitotrophic & larvae nourished on internal resources \\
\hline Planktotrophic & larvae feed on planktonic material \\
\hline \multicolumn{2}{|l|}{ Duration of planktonic larval stage } \\
\hline None & no planktotrophic larval stage \\
\hline Planktotrophic_days & planktotrophic larvae during days \\
\hline Planktotrophic_month & planktotrophic larvae during month(s) \\
\hline
\end{tabular}


species usually express within a trait, the fuzzy coding procedure (Chevenet et al. 1994) was used, allowing species relative affinity to modalities to differentiate, summing up to 1 within a trait. The fuzzy coded trait expressions of individual species were scaled up by correcting each modality for species- and sample-specific abundances, creating a site-by-trait matrix.

Groups of traits expected to contribute to the magnitude of each property at a site were defined (i.e., functional trait groups; see Table 1) and each species was then assigned to a single functional trait subgroup (not fuzzy coded) that represented its maximum potential for benthic bioturbation, stability and dispersal (Figs. 2, 3, Table 2). For estimating benthic bioturbation potential, traits representing faunal environmental position, sediment reworking mode, and maximum size were considered and five subgroups representing different degrees or types of bioturbation were defined (Table 2). To estimate the stability of the benthic community, species' longevity and maximum size were used to define three subgroups representing different contributions to community stability (Table 2). Finally, the potential for larval dispersal (here represented by reproductive frequency, larval type, and the duration of planktonic larval stage) has

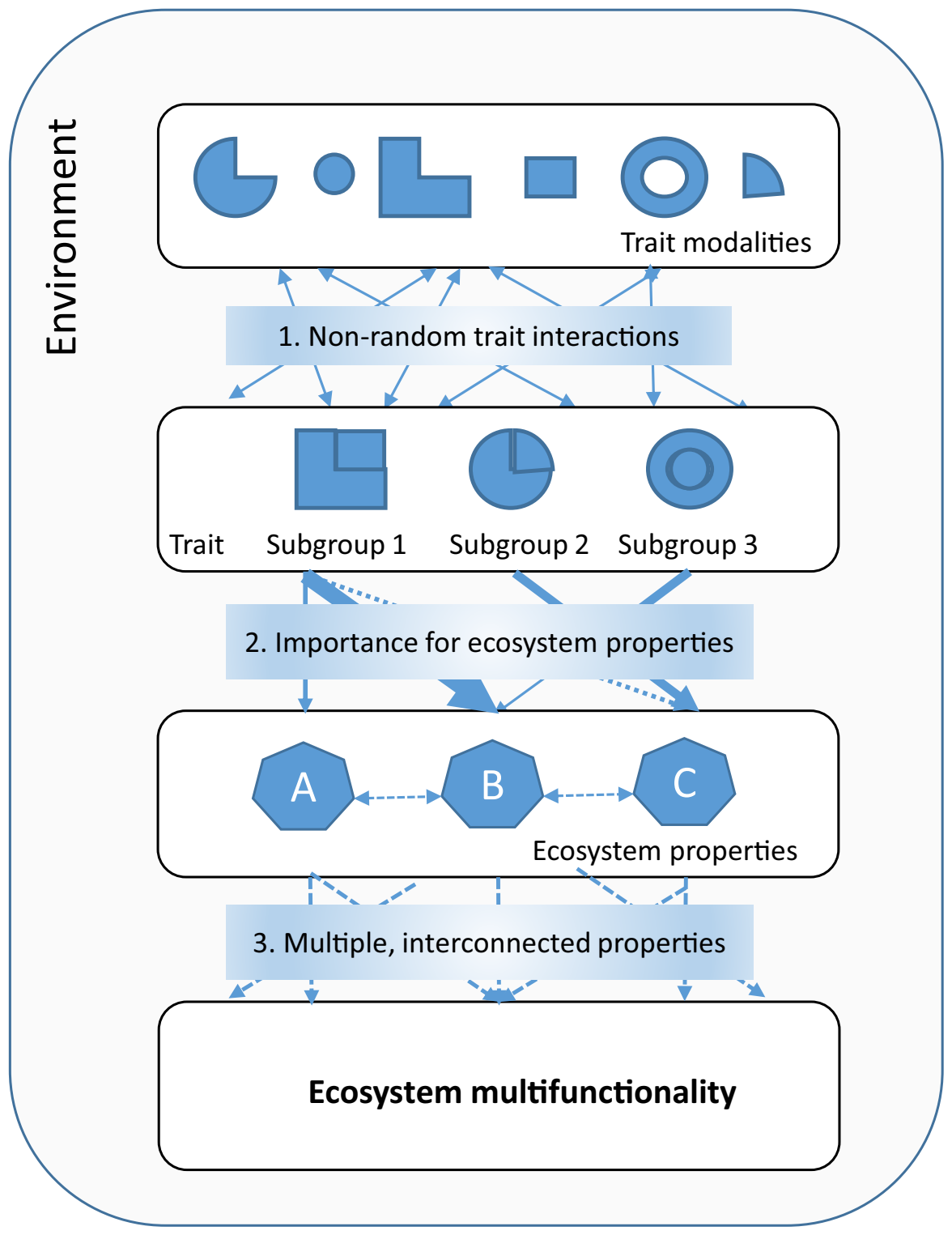

FIG. 2. Conceptual figure identifying (spatial) patterns in ecosystem multifunctionality by using groupings of biological traits. As a result of environmental filtering, species' traits do non-randomly interact (1) enabling the identification of subgroups of traits having differing importance (2; width of arrows) for directing ecosystem properties. The simultaneous contribution of species to multiple, interacting properties (3) is considered by combining several properties in an estimation of ecosystem multifunctionality. [Color figure can be viewed at wileyonlinelibrary.com] 


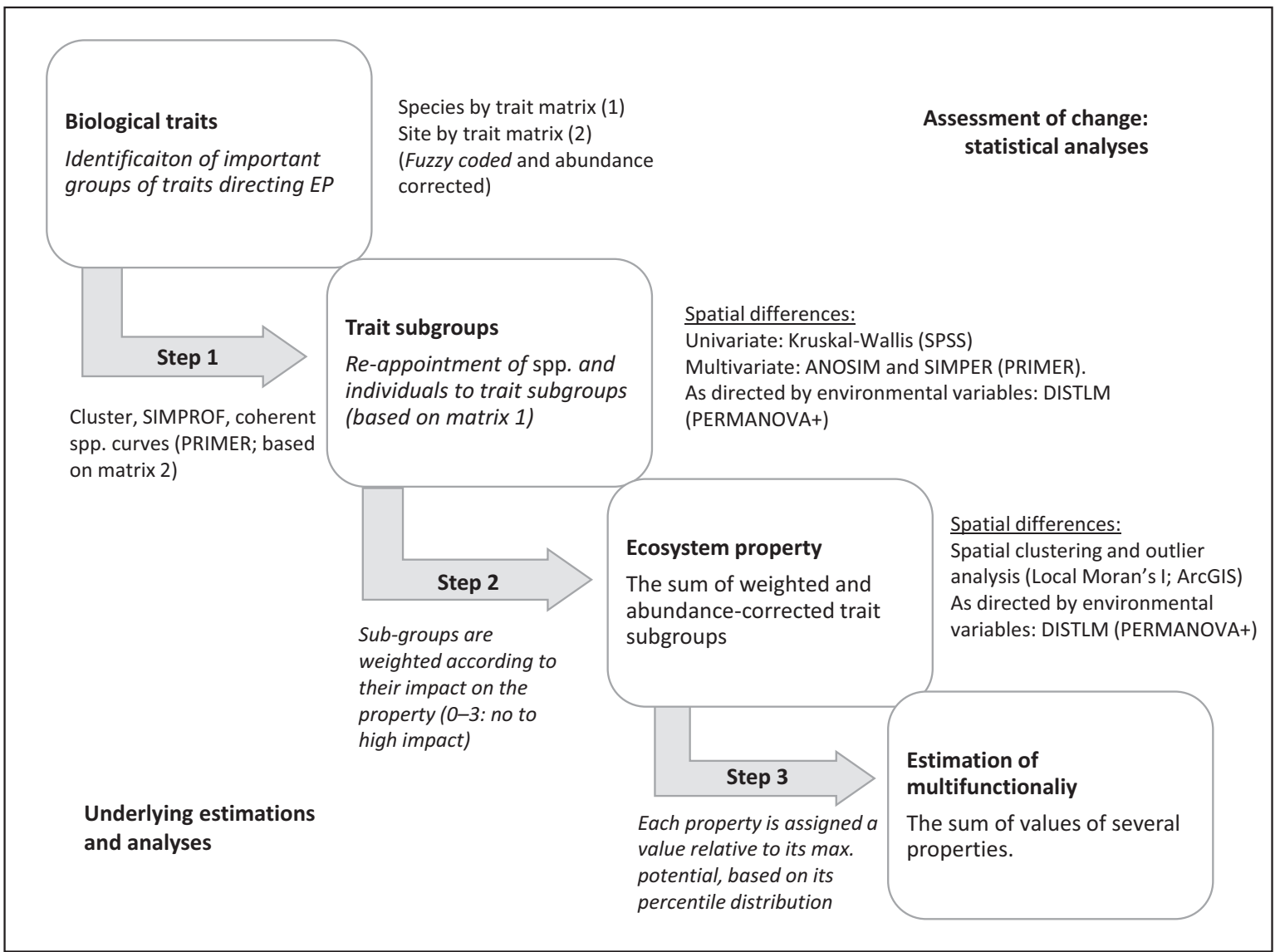

FIG. 3. Template for using biological trait groupings when exploring variation in ecosystem properties (EP) and multifunctionality. Groups of traits important for directing ecosystem properties are selected. Subgroups of traits are identified by expert opinion and statistically confirmed from a site-by-trait matrix (Step 1). The subgroups are scored according to their estimated (0-3; no to high) impact on the property under consideration (Step 2). The cumulative expression of one property represents the sum of its weighed and abundance-corrected trait sub-groups. For evaluating ecosystem multifunctionality, each property is ranked (based on its percentile distribution) and assigned a value relative to its maximum (max., Step 3). Individual property values are summed to create an overall estimation of ecosystem multifunctionality. Univariate as well as multivariate analyses can be used for assess change. Please note that Step 1-3 also correspond to the numbers given in Fig. 2. All phases involving literature-based assessments or expert judgement are shown in italic typeface.

traditionally been considered important for re-colonization over large scales (e.g., Whitlatch et al. 1998, Pilditch et al. 2015). Four subgroups representing different degrees of larval dispersal in space and time were defined (Table 2).

For each functional-trait grouping, the relations between the biological trait modalities comprising the subgroups were explored by using multivariate analyses (e.g., Figs. 2, 3). The trait similarity matrix underlying the analyses was based on Whittaker's index of association, calculated on square-root-transformed and standardized data. Starting from the site-by-trait matrix, SIMPROF 2 and 3 tests were performed to objectively detect associations between trait modalities for each ecosystem property. SIMPROF 2 was used to test whether the combinations of biological traits exhibited by a species were random or whether there is some structure (relationship) between traits. Sub-groups of traits were further identified with cluster analyses (complete linkage) and
SIMPROF 3 was used to explore the uniformity of trait similarities within subgroups (Clarke et al. 2014). Finally, the trait combinations were inspected with coherent species curves and compared with the subgroups identified by expert opinion (Fig. 3).

\section{Spatial patterns in benthic ecosystem properties}

To identify functionally diverse sites, the number of species, trait modalities and functional trait subgroups were calculated for each site. The relationship between these variables was examined with nonparametric Spearman $\rho$. The nonparametric Kruskal-Wallis test was used to detect differences in the number of functional trait sub-groups between water basins. Significance values for pairwise comparisons were adjusted by the Bonferroni correction for multiple tests (Fig. 3).

Spatial differences in functional trait sub-groups between water basins were examined and the subgroups 
TABLE 2. Sub-groups of traits depicting benthic ecosystem properties such as bioturbation, stability and larval dispersal.

\begin{tabular}{|c|c|c|c|c|c|c|}
\hline \multirow[b]{3}{*}{ Species } & \multicolumn{6}{|c|}{ Groupings of biological traits } \\
\hline & \multicolumn{2}{|c|}{ Bioturbation } & \multicolumn{2}{|c|}{ Stability } & \multicolumn{2}{|c|}{ Dispersal } \\
\hline & Sub-groups & Impact score & Sub-groups & Impact score & Sub-groups & Impact score \\
\hline Halicryptus spinulosus & B5 & 3 & $\mathrm{~S} 3$ & 3 & D2 & 1 \\
\hline Cyanophthalma obscura & B3 & 2 & $\mathrm{~S} 1$ & 1 & D2 & 1 \\
\hline Macoma balthica & B4 & 3 & $\mathrm{~S} 3$ & 3 & D4 & 3 \\
\hline Mytilus trossulus & $\mathrm{B} 0$ & 0 & $\mathrm{~S} 3$ & 3 & D4 & 3 \\
\hline Mya arenaria & B4 & 3 & $\mathrm{~S} 3$ & 3 & D4 & 3 \\
\hline Cerastoderma spp. & B3 & 2 & $\mathrm{~S} 3$ & 3 & D4 & 3 \\
\hline Anodonta spp. & B3 & 2 & $\mathrm{~S} 3$ & 3 & $\dagger$ & \\
\hline Theodoxus fluviatilis & $\mathrm{B} 1$ & 1 & $\mathrm{~S} 2$ & 2 & D2 & 1 \\
\hline Valvata spp. & $\mathrm{B} 1$ & 1 & $\mathrm{~S} 1$ & 1 & D2 & 1 \\
\hline Hydrobia spp. & $\mathrm{B} 1$ & 1 & $\mathrm{~S} 1$ & 1 & D3, D4 & 3 \\
\hline Potamopyrgus antipodarum & $\mathrm{B} 1$ & 1 & $\mathrm{~S} 1$ & 1 & D2 & 1 \\
\hline Bithynia tentaculata & $\mathrm{B} 1$ & 1 & $\mathrm{~S} 1$ & 1 & D2 & 1 \\
\hline Limapontia capitata & $\mathrm{B} 1$ & 1 & $\mathrm{~S} 1$ & 1 & D3 & 2 \\
\hline Alderia modesta & B1 & 1 & $\mathrm{~S} 1$ & 1 & D3 & 2 \\
\hline Marenzelleria spp. & B5 & 3 & $\mathrm{~S} 2$ & 2 & D4 & 3 \\
\hline Bylgides sarsi & B3 & 2 & $\mathrm{~S} 1$ & 1 & D4 & 3 \\
\hline Nereis diversicolor & B5 & 3 & $\mathrm{~S} 2$ & 2 & D1 & 1 \\
\hline Polydora redeki & $\mathrm{B} 2$ & 2 & $\mathrm{~S} 1$ & 1 & D4 & 3 \\
\hline Pygospio elegans & $\mathrm{B} 2$ & 2 & $\mathrm{~S} 1$ & 1 & D4 & 3 \\
\hline Manayunkia aestuarina & $\mathrm{B} 2$ & 2 & $\mathrm{~S} 1$ & 1 & D2 & 1 \\
\hline Idotea spp. & B0 & 0 & $\mathrm{~S} 1$ & 1 & $\mathrm{D} 2$ & 1 \\
\hline Saduria entomon & B3 & 2 & $\mathrm{~S} 3$ & 3 & D1 & 1 \\
\hline Asellus aquaticus & $\mathrm{B} 0$ & 0 & $\mathrm{~S} 2$ & 2 & D1 & 1 \\
\hline Jaera spp. & $\mathrm{B} 0$ & 0 & $\mathrm{~S} 1$ & 1 & D2 & 1 \\
\hline Gammarus spp. & $\mathrm{B} 1$ & 1 & $\mathrm{~S} 1$ & 1 & D2 & 1 \\
\hline Monoporeia affinis & B3 & 2 & $\mathrm{~S} 2$ & 2 & D1 & 1 \\
\hline Corophium volutator & B5 & 3 & $\mathrm{~S} 1$ & 1 & D1 & 1 \\
\hline Crangon crangon & B3 & 2 & $\mathrm{~S} 2$ & 2 & D4 & 3 \\
\hline Chironomidae & $\mathrm{B} 2$ & 2 & $\mathrm{~S} 1$ & 1 & D1 & 1 \\
\hline Chironomus spp. & $\mathrm{B} 2$ & 2 & $\mathrm{~S} 1$ & 1 & D1 & 1 \\
\hline Ephemeroptera & B2 & 2 & $\mathrm{~S} 1$ & 1 & D1 & 1 \\
\hline Trichoptera & $\mathrm{B} 2$ & 2 & $\mathrm{~S} 1$ & 1 & D2 & 1 \\
\hline
\end{tabular}

Notes: The estimated contribution of each subgroup to the overall potential for a benthic ecosystem property is scored as 0 , no impact; 1, low; 2, medium; and 3, high impact. The following subgroupings were identified: bioturbation (B; 0 , no transport or pelagic; 1, small individual or epibenthic surface modifier; 2, very small individual or tube dweller or infauna top; 3 , biodiffuser, infauna top; 4, large biodiffuser, infauna bottom; and 5, medium-sized gallery diffuser); stability (S; 1, small, short-lived species [ $<2 \mathrm{yr}$ ]; 2, medium-sized species with a life span of 2-5 yr; 3, large, long-lived species [5-10 yr or more]); dispersal (D; 1, semelparous reproductive frequency, direct development without a planktotrophic larval stage; 2 , annual reproductive frequency, direct development, no planktotrophic larval stage; 3, lecitotrophic larvae with a short planktotrophic larval stage; 4, annually episodic or protracted reproductive frequency, planktotrophic larvae during months).

$\dagger$ Not included in juvenile dispersal potential, as reproduction in Anodonta spp. involves a parasitic stage (in fish; Haukioja and Hakala 1978), complicating the dispersal assessment.

contributing to these were identified (one-way ANOSIM and SIMPER of Bray-Curtis similarities [Fig. 3]). The BrayCurtis measures were based on square-root-transformed data, and the analyses were performed with the PRIMER 7 software (Clarke et al. 2014, Clarke and Gorley 2015).

Finally, in order to estimate the cumulative expression of each property (i.e., bioturbation, stability, and juvenile dispersal) at a site, the functional trait subgroups were scored according to their weighted impact on each property. Trait groupings estimated to have a greater impact on the considered property got a higher value (0, no impact; 1 , low; 2, medium; and 3, high; Table 2,
Fig. 2). The sum of these scored, abundance-corrected trait groupings represent the cumulative expression of a property at a site (Fig. 3).

\section{Estimation of multifunctionality}

All three properties, i.e., bioturbation, stability, and juvenile dispersal were considered when estimating the potential for benthic ecosystem multifunctionality (EMF). Each property was assigned a value relative to its observed cumulative expression in the study area. Observations were divided into percentiles (the 25th, 
50th, 75th, and 95th percentile), where observations in the first quartile got the lowest functional value (1), the second a value of 2 , and so on, while observations above the 95th percentile were given a value of 5 . Values were then summed across properties to provide an overall estimation of benthic EMF at a site (Figs. 2, 3). Spatial clustering and outlier analysis (Local Moran's I; Anselin 1995) was used to analyze the standardized spatial structure of each cumulative property and the estimation of EMF separately (Fig. 3). Local Moran's $I z$ scores were used to find clusters of sites with high values $(\mathrm{HH})$ and low values (LL) relative to the average of all sites, and outlier sites that have either high values (HL) or low values (LH) relative to neighboring sites. The false discovery rate method was used to correct $P$ values for multiple tests (Benjamini and Hochberg 1995) and data was fourth-root transformed prior to analyses to reduce skewness. The spatial analyses were conducted in ArcGIS 10.2 (ESRI, Redlands, California, USA).

\section{Environmental parameters directing benthic ecosystem functionality}

Distance based linear models (DISTLM) were used to identify environmental parameters most related to the spatial patterns in the functional trait subgroups representing each property and to the estimate of EMF (Fig. 3) using the subset of 72 sites with the additional environmental parameters available. The response matrix consisted of site data of the abundance-corrected functional trait subgroups or the overall estimation of EMF, while environmental parameters were depth (m), wave exposure, sediment organic matter (\%), grain size $(\%)$, bottom and surface water temperature $\left({ }^{\circ} \mathrm{C}\right)$, bottom water salinity, oxygen content (\%), and the Secchi depth. Due to high observed correlations between sediment organic matter and mud and coarse sand with both very coarse sand and fine sand, models were constrained to only use one of each of these sets. Final inclusion of predictor variables in the model was based on AIC criteria and a forward as well as a backward selection procedure. The DISTLM analyses were performed with the PRIMER PERMANOVA+ package (Anderson et al. 2008).

\section{RESULTS}

\section{Groupings of biological traits}

SIMPROF tests suggested that there were strong associations between trait modalities important for benthic bioturbation (SIMPROF 2, $\mathrm{Pi}=12.67, P=0.0001$; SIMPROF 3, $\mathrm{Pi}=17.34, P=0.0001$ ). Cluster analysis distinguished five different functional trait subgroups that were combined with, at least, $64 \%$ similarity (Table 2; Appendix S2: Fig. S1A). The traits "pelagic" and "no sediment transport" could not be statistically separated from one another and were thus considered as one subgroup (impact scoring for overall bioturbation potential; 0).
Another subgroup was created by traits describing small individuals and epibenthic surface modifiers, while the next sub-group consisted of tube dwellers and infauna in the top sediment layer (impact scoring 1 and 2, respectively). The traits "large" and "biodiffuser" were statistically inseparable, and were grouped together with "infauna bottom" creating the following subgroup (impact scoring 3). Finally, medium-sized gallery diffusers created the last functional sub-group depicting benthic bioturbation (impact scoring 3). However, the hypothesized trait combination "biodiffuser, in the upper part of the sediment (top $2 \mathrm{~cm}$ )" was not discerned by the cluster analyses. It was still accounted for in the subsequent analyses, and scored as having a medium impact (2) for the overall bioturbation potential (Table 2; Appendix S2: Fig. S1A).

For traits related to the stability of the benthic community, three different trait groupings were discerned (SIMPROF 2, Pi $=12.92, P=0.0001$; SIMPROF 3, $\mathrm{Pi}=12.93, P=0.0001)$. The traits large body size and a life span of 5-10 yr could not be statistically separated from one another (impact scoring for overall stability potential 3). Likewise, the traits medium size and a longevity of 2-5 yr were grouped together (impact scoring 2 ). The third trait combination described small (very small and small) and short-lived ( $<1 \mathrm{yr}, 1-2 \mathrm{yr})$ species (impact scoring 1; Table 2; Appendix S2: Fig. S1B).

Traits describing juvenile dispersal potential also showed associations between modalities (SIMPROF 2, $\mathrm{Pi}=13.27$, $P=0.0001$; SIMPROF 3, $\mathrm{Pi}=29.27, P=0.0001$ ). Cluster analysis discerned three different subgroupings, within which trait modalities showed at least $62 \%$ similarity (Table 2; Appendix S2: Fig. S1C). Trait attributes describing a semelparous reproductive frequency, direct development, and no planktotrophic larval stage were closely grouped together (impact scoring for overall dispersal potential, 1). Lecitotrophic development strategy and a short planktotrophic larval stage (days) could not be statistically separated, creating another functional subgroup (impact scoring, 2). The third grouping, describing species with annually protracted and episodic reproductive frequencies and planktotrophic development with larvae in the plankton during month(s), was considered to have high impact (3) on the community dispersal potential. Still, one additional combination of attributes was predicted from the expressed benthic features, namely "annual reproductive frequency," "direct development," and "no planktotrophic larval stage" (impact scoring, 1). The subgroupings of different trait modalities were supported by the pattern displayed by coherent trait curves (results not shown).

\section{Spatial variation in subgroups of functional traits}

The number of biological trait modalities and functional trait subgroups observed at a site were significantly correlated with each other and with the number of species ( $\rho \geq 0.8, P<0.001, N=426$ ). The average number of species at the 427 sites was $5.0 \pm 2.6$ (mean $\pm \mathrm{SD}$ ), while 


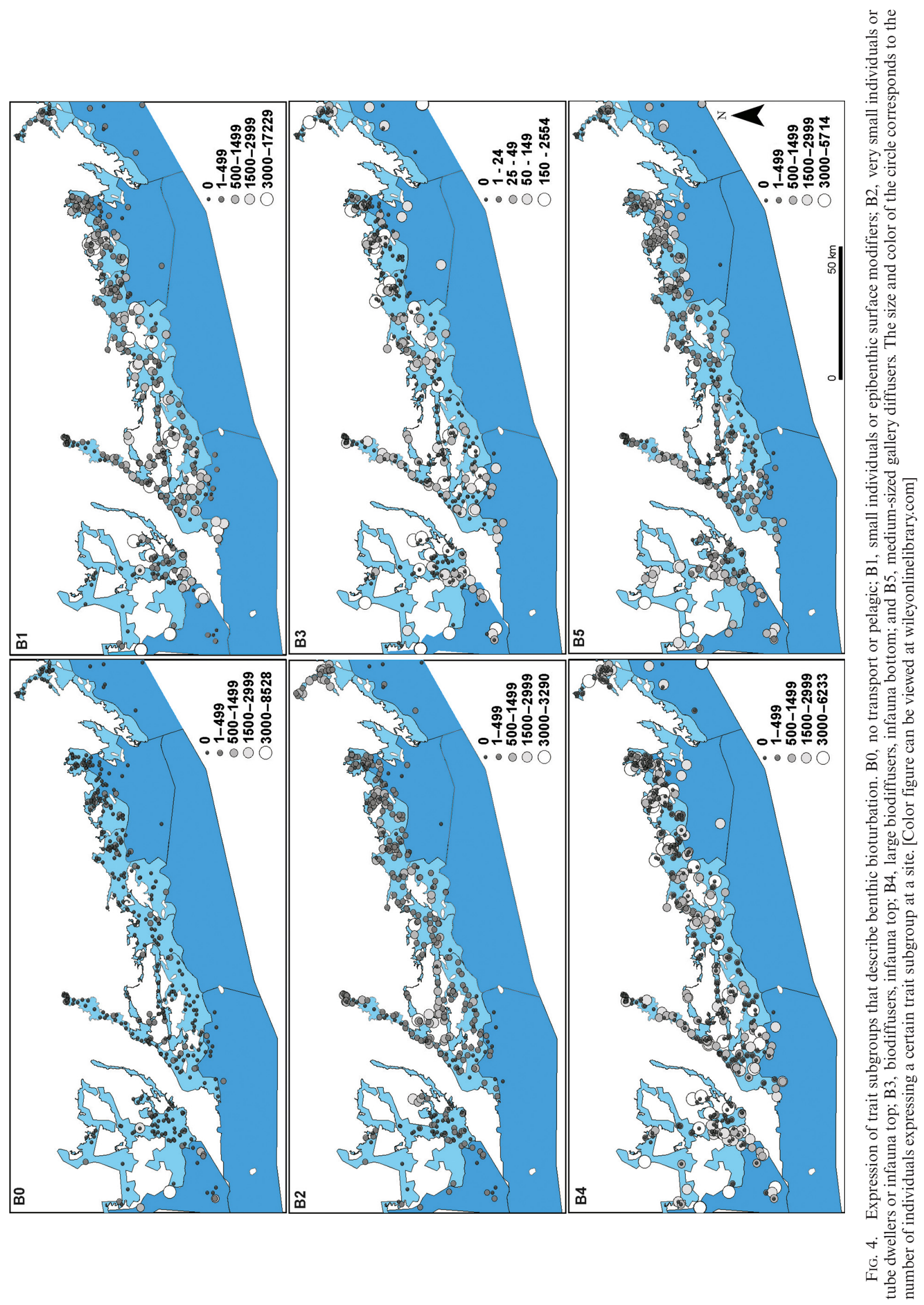


a maximum of 15 species was found at a site. The number of biological trait modalities and functional-trait subgroups were, on average, $18.7 \pm 5.4$ and $8.2 \pm 2.7$, respectively, with maximum values of 26 and 13 (Appendix S3: Table S1). In the outermost water basin both high abundances and a high number of functional trait sub-groups was observed (Appendix S3: Table S1). Benthic communities in this basin differed in terms of functional trait subgroups to inner archipelago basins, which had lower functional diversity (Kruskal-Wallis nonparametric test; $\chi^{2}=76.18, \mathrm{df}=16, P<0.001$, Appendix S3: Table S1).

\section{Bioturbation potential}

Considering the entire data set, "small, epibenthic surface modifiers" was the dominant sub-group describing the benthic bioturbation potential in the study area (in total $36 \%$ ), together with the sub-groups "medium-sized gallery diffusers" (22\%) and "large, deep-burrowing biodiffusers" $(27 \%)$. Very small tube dwellers in the uppermost part of the sediment contributed $12 \%$ to the bioturbation potential. Few individuals belonged to the sub-groups of "biodiffusers, top sediment" or to "no effect" on sediment reworking ( $\sim 3 \%$; Fig. 4). Differences occurred between basins (ANOSIM, Global $R=0.14, P=0.0001$ ), with the outer archipelago areas dominated by gallery diffusers and large biodiffusers in bottom sediments (Figs. 4, 5A). Several basins situated in the inner archipelago were distinguished by a dominance of very small tube dwellers in the uppermost layer of the sediment (Figs. 4, 5A) Three sub-basins (Storfjärden, Inkoo Degerö, Inko Fagervik) had an even distribution of several functional trait subgroups, and differed significantly from both inner and outer archipelago areas (Figs. 4, 5A). The cumulative expression of bioturbation was highest to the west of the Hanko Peninsula and in two adjacent basins west of Porkkala Peninsula, while the innermost sub-basins had a low cumulative expression (Fig. 5B, C).

\section{Community stability}

The majority of individuals in the study area belonged to the trait sub-group of "small (very small and small) and short-lived ( $<1,1-2 \mathrm{yr})$ " individuals, while $20 \%$ belonged to the subgroup describing "medium-sized individuals, 2-5 yr." The share of individuals in the subgroup "large (1) and long-lived (5-10 yr)" was 30\% (Appendix S4: Fig. S1). There were few differences in stability subgroupings between areas (ANOSIM Global $R=0.106, P=0.0001$ ). However, four of the inner basins were significantly separated from $75 \%$ of the other areas
(ANOSIM, $P<0.05$ ), being heavily dominated by the sub-group of "small, short-lived individuals" (Appendix S4: Figs. S1, S2A). One of the basins west of Hanko Peninsula was distinguished from the other areas due to the dominance of the sub-group "medium sized, 2-5 yr individuals," which resulted in a high average betweensample similarity (SIMPER: 74.5\%). In several outer subbasins, sub-groups describing "large, long-lived" as well as "medium-sized, 2-5 yr" individuals played an important role for the stability of the community (Appendix S4: Figs. S1, S2A). The cumulative expression of stability was highest in two adjacent basins west of Hanko Peninsula and in two adjacent basins west of Porkkala Peninsula. In contrast, the lowest cumulative expression was observed in the innermost basin east of Hanko Peninsula (Appendix S4: Fig. S2B, C).

\section{Juvenile dispersal potential}

The majority of individuals $(75 \%)$ in the study area belonged to the sub-group having a very high potential for dispersal (i.e., annual reproductive frequency with a long planktotrophic larval stage). $21 \%$ of the individuals were semelparous, with direct development and no planktotrophic larval stage. The rest belonged to the sub-group of "local brooders with planktonic larvae," or had a direct development, but reproduced during an annually protracted period (Appendix S5: Fig. S1).

There were few pronounced differences in dispersal groupings between basins (ANOSIM Global $R=0.10$, $P=0.0001)$, but outer archipelago basins differed from the inner ones $(R>0.3, \quad P<0.001$; Appendix $\mathrm{S} 5$ : Fig. S2A). Individuals belonging to sub-groups describing an annually episodic or protracted reproductive frequency and a long planktotrophic larval phase dominated the outer basins (and contributed to $>75 \%$ of within area similarities), while individuals with a semelparous reproductive frequency and direct development comprised up to $60 \%$ of within area similarities in less exposed basins (SIMPER, Appendix S5: Fig. S1). The cumulative expression of dispersal was highest in two adjacent basins west of Hanko Peninsula and west of Porkkala Peninsula, respectively, and lowest in inner basins (Appendix S5: Fig. S2B, C).

\section{Estimation of benthic ecosystem multifunctionality}

Benthic EMF was highest in two adjacent outer archipelago basins west of Hanko Peninsula and two west of the Porkkala Peninsula (Fig. 6). Interestingly, one of these sub-basins (Bromarv), had low species diversity

FIG. 5. (A) For benthic bioturbation, the most significant differences (i.e., ANOSIM; pairwise comparisons, $R>0.25$, $P<0.05$ ) in functional trait subgroups (cf. Fig. 4) between water bodies are marked. The water bodies with similar shading are statistically inseparable, but significantly different from water bodies marked with other shading. (B) The cumulative expression of benthic bioturbation. (C) Anselin local Moran's $I$ indicates statistically significant $(P<0.05)$ cluster of sites with high $(\mathrm{HH})$ and low (LL) cumulative expression of bioturbation. Sites with high values surrounded by sites with low values are marked with HL, while LH mark sites where low values are surrounded by high. [Color figure can be viewed at wileyonlinelibrary.com] 

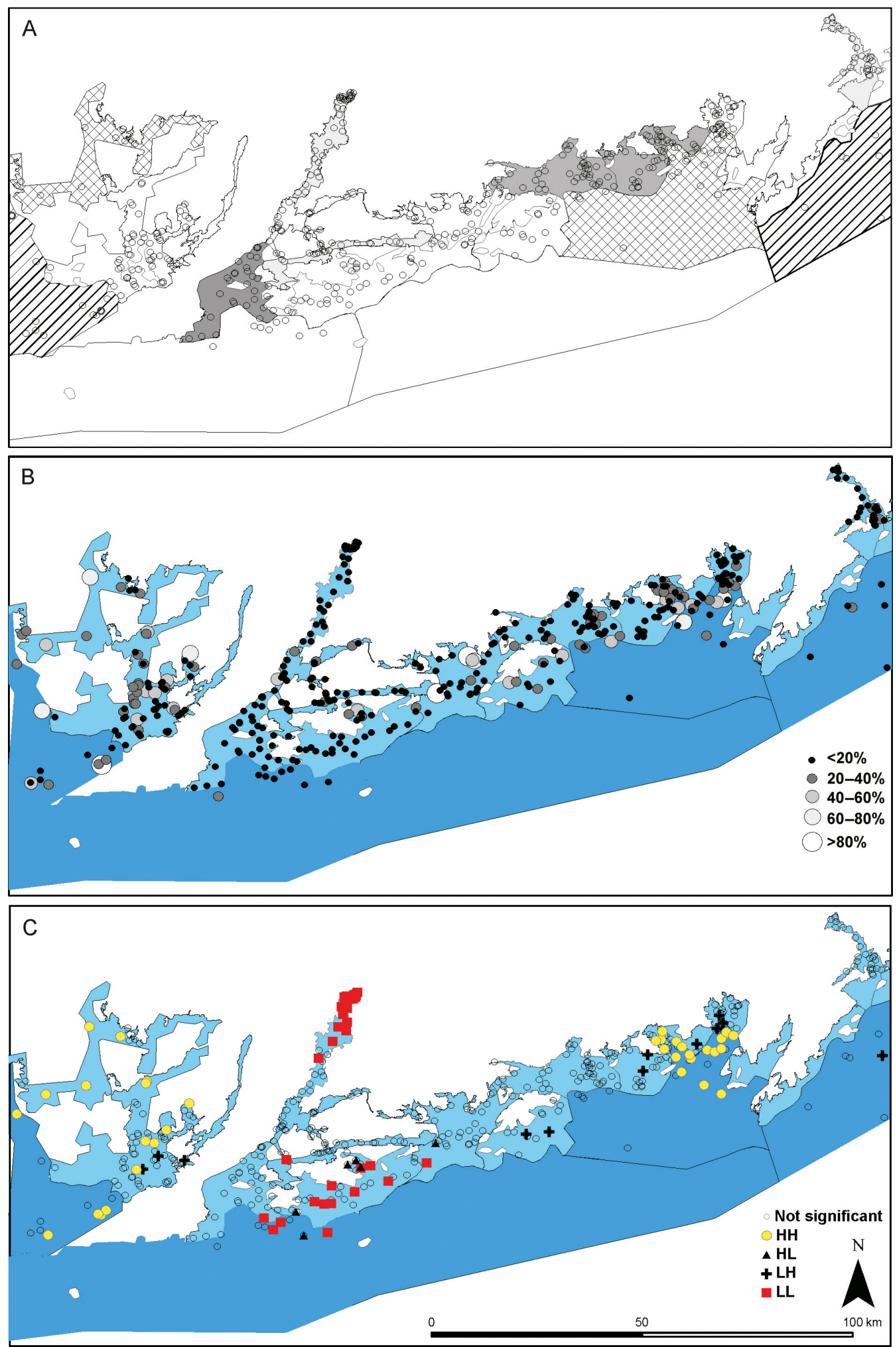


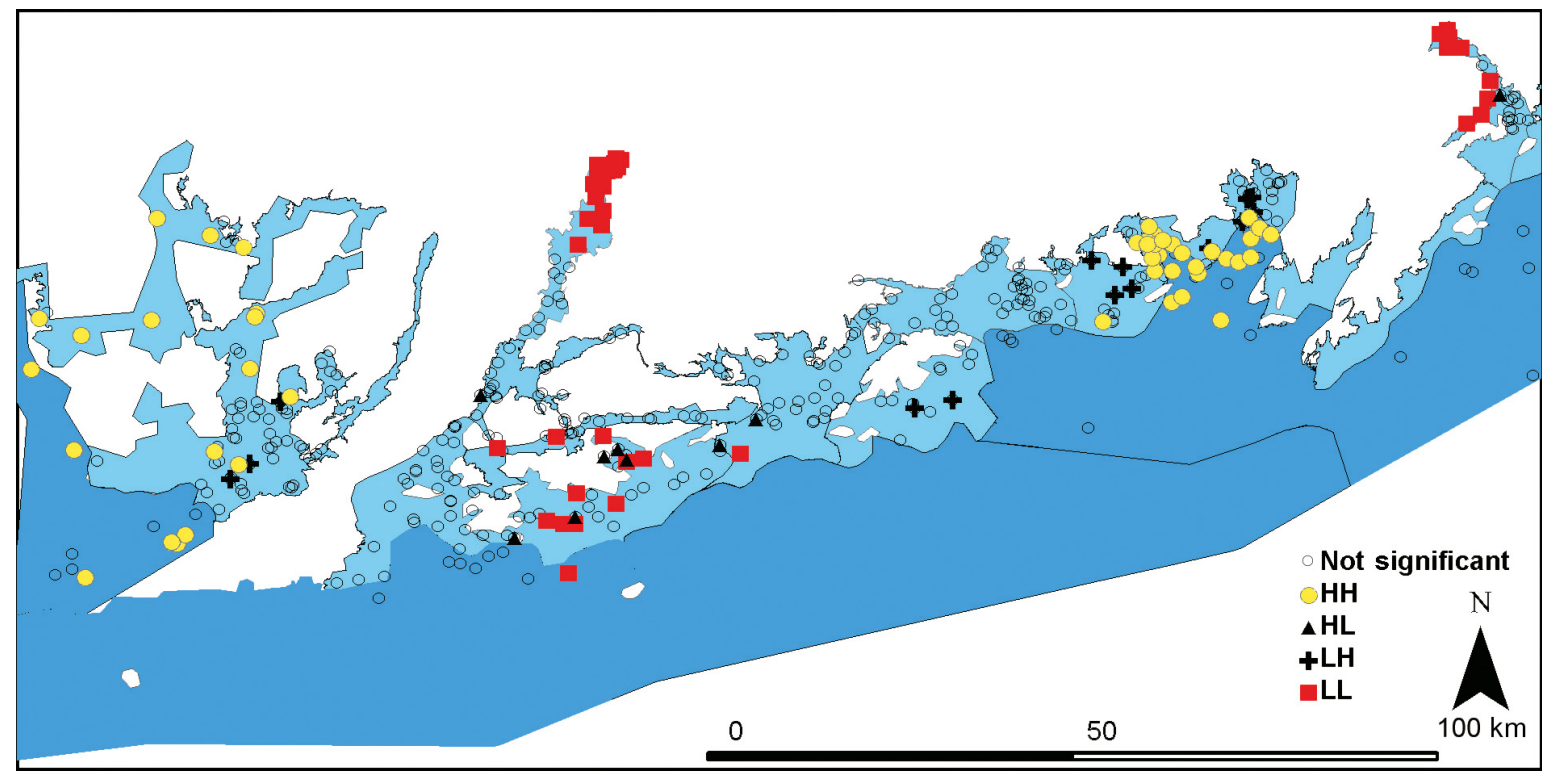

FIG. 6. Overall estimation of benthic ecosystem multifunctionality along the southwest Finnish coast. Three ecosystem properties are assessed, i.e., bioturbation, stability, and juvenile dispersal. Each property was assigned a functional value relative to its maximum, and the individual property values were summed to reach an overall estimation of benthic ecosystem multifunctionality. Clusters of sites with values of similar magnitude are marked, as well as outliers $(P<0.05$, for explanation of labels, see Fig. 5). [Color figure can be viewed at wileyonlinelibrary.com]

TABLE 3. Results of variation partitioning analyses (DISTLM) quantifying the marginal and partial effects of environmental variables on the functional trait subgroups describing benthic bioturbation, stability and juvenile dispersal, as well as on the overall estimation of benthic ecosystem multifunctionality (EMF).

\begin{tabular}{|c|c|c|c|c|c|c|c|c|c|c|c|c|}
\hline \multirow[b]{2}{*}{ Variable } & \multicolumn{3}{|c|}{$\begin{array}{c}\text { Bioturbation } \\
(\mathrm{AIC}=471.0 \\
\left.R^{2}=32.8\right)\end{array}$} & \multicolumn{3}{|c|}{$\begin{array}{c}\text { Stability } \\
(\mathrm{AIC}=446.0 \\
\left.R^{2}=38.9\right)\end{array}$} & \multicolumn{3}{|c|}{$\begin{array}{c}\text { Juvenile dispersal } \\
(\mathrm{AIC}=437.2 \\
\left.R^{2}=46.5\right)\end{array}$} & \multicolumn{3}{|c|}{$\begin{array}{c}\text { EMF } \\
(\mathrm{AIC}=110.2 \\
\left.R^{2}=62.4\right) \\
\end{array}$} \\
\hline & Marg. & Part. & $\mathrm{AIC}$ & Marg. & Part. & AIC & Marg. & Part. & AIC & Marg. & Part. & AIC \\
\hline OM $(\%)$ & $10.8^{*}$ & $6.8 * *$ & 473.6 & $13.7 * *$ & $10.2 * *$ & 453.4 & $18.5^{* *}$ & $18.5^{* *}$ & 454.5 & $36.6 * *$ & $36.6^{* *}$ & 134.1 \\
\hline $\mathrm{O}_{2}(\%)$ & $10.1 * *$ & $8.9 * *$ & 477.4 & $11.0^{* *}$ & $4.9 *$ & 446.1 & $10.2 * *$ & $2.9 * * *$ & 439.9 & $14.0^{*}$ & $2.3 \mathrm{~ns}$ & 120.1 \\
\hline Salinity & $7.9 * *$ & $4.9 *$ & 471.0 & $8.6^{*}$ & $6.8 * *$ & 449.1 & $10.4^{* *}$ & $4.3^{*}$ & 442.2 & $8.5^{* * *}$ & $3.7^{*}$ & 121.3 \\
\hline Temp.diff. $\left({ }^{\circ} \mathrm{C}\right)$ & $12.2 * *$ & $12.2 * *$ & 482.4 & $17.0^{* *}$ & $17.0 * *$ & 459.9 & $7.5^{*}$ & $1.9 \mathrm{~ns}$ & 438.4 & $2.5 \mathrm{~ns}$ & $5.0 *$ & 114.7 \\
\hline Depth (m) & $10.6^{* *}$ & & & $14.9 * *$ & & & $6.9^{*}$ & $13.8 * *$ & 437.2 & $0.005 \mathrm{~ns}$ & & \\
\hline Temp. $\left({ }^{\circ} \mathrm{C}\right)$ & $10.2 * *$ & & & $14.9^{* *}$ & & & $7.1 *$ & & & $1.2 \mathrm{~ns}$ & $2.1 \mathrm{~ns}$ & 111.5 \\
\hline Secchi depth & $6.0^{*}$ & & & $6.4^{*}$ & & & $9.9 * *$ & & & $11.4^{*}$ & & \\
\hline Exposure & $7.0 * *$ & & & $10.0^{* *}$ & & & $9.6 * *$ & & & $8.0 * * *$ & & \\
\hline Gravel & $1.1 \mathrm{~ns}$ & & & $1.0 \mathrm{~ns}$ & & & $2.5 \mathrm{~ns}$ & & & $7.1 * * *$ & & \\
\hline Very coarse sand & $4.8^{*}$ & & & $5.5^{* * *}$ & & & $11.1^{* *}$ & $2.9 * * *$ & 441.1 & $14.8 * *$ & & \\
\hline Fine sand & $3.7 * * *$ & & & $4.2 * * *$ & & & $6.8^{*}$ & & & $10.3^{*}$ & & \\
\hline Very fine sand & $9.7 * *$ & & & $12.3 * *$ & & & $17.3^{* *}$ & $2.8 * * *$ & 438.7 & $34.5^{* *}$ & $2.0 \mathrm{~ns}$ & 110.2 \\
\hline
\end{tabular}

Notes: The marginal test (Marg.) represents the relationship between the response data cloud and an individual explanatory variable alone, while the partial (Part.) test describes this relationship after fitting the other variables. AIC, Akaike information criterion, where lower values describe a better model; OM, organic matter; Temp.diff., difference between surface and bottom water temperature $\left({ }^{\circ} \mathrm{C}\right)$.

$* P<0.05, * * P<0.01,{ }^{* * *} P<0.001, \mathrm{~ns} P>0.05$

(Appendix S3: Table S1) but high EMF, due to the presence of a species complex important for all of the considered benthic ecosystem properties, Marenzelleria spp. Clusters of sites with low EMF in the innermost archipelago were also identified, while outliers were common in one sub-basin situated in the middle archipelago (Fig. 6).

\section{Environmental variables related to functional trait groupings and benthic ecosystem multifunctionality}

The most important environmental drivers of the functional trait subgroups describing benthic bioturbation were temperature stratification of the water column, 
bottom water oxygen and salinity content, and the sediment organic matter content (total $R^{2}: 32.8 \%$, Table 3 ). All trait subgroups describing bioturbation were represented in well-oxygenated, coarse, sandy sediments, while medium-sized gallery diffusers and, especially, very small tube dwellers in the uppermost part of the sediment became more common as bottom water oxygen content decreased and sediment organic matter content increased.

Environmental parameters could describe a large part of the variation in trait subgroups portraying benthic stability (total $R^{2}$ : $38.9 \%$; Table 3 ). Again, temperature stratification, sediment organic matter content, bottom water oxygen and salinity were the most important environmental drivers (Table 3). All trait groupings were most abundant at sites with high oxygen and salinity values, where sediment organic matter was low.

Functional trait subgroups describing juvenile dispersal were foremost predicted by sediment organic matter and depth (total $R^{2}: 46.5 \%$, Table 3). Functional trait subgroups representing a higher dispersal potential were found to be more common at sites with coarser sediments, while sites with higher organic matter content and less oxygen and salinity in bottom waters (oxygen and salinity together explaining $7.2 \%$ of the total variation, Table 3 ), were characterized by individuals with a lower dispersal potential, displaying a semelparous reproductive frequency, direct development, and no planktotrophic larval phase.

The variation in benthic EMF was strongly related to single environmental predictors describing sediment properties, water column stratification as well as bottom water salinity (Table 3). Overall, $62.4 \%$ of the variation in EMF could be explained, with sediment organic matter alone being able to explain $36.6 \%(P=0.0001)$ of the total variation (Table 3 ).

\section{DiscusSION}

Our study is able to identify coastal areas (current marine management basins) with high and low potential for benthic bioturbation, stability, and juvenile dispersal, based on groupings of biological traits. We also demonstrate that the functional trait subgroups are the ones that occur naturally for the resident species and by scoring them according to their weighted ecological impact, an actual representation of benthic ecosystem properties was gained. We furthermore offer an overall estimate of benthic ecosystem multifunctionality (EMF), which sums over the considered properties. Importantly, we show that a large part of the spatial differences in trait groupings as well as the estimate of multifunctionality is explained by environmental information. Hence, we argue that this study can provide a template for estimating differences in ecosystem functionality over large geographical scales, information sorely needed in marine management and spatial planning efforts striving to balance the utilization with the preservation of natural resources.
The quantification of ecosystem functions and services in marine areas is complicated by ecological complexity, functional scale dependency, and a lack of data (Townsend et al. 2014) and there is a need for alternative approaches to evaluate ecosystem functionality. This has been increasingly recognized and studies to date have estimated the spatial variability in ecosystem functions by, for example, considering variation in the number of traits important for ecosystem processes (Rees et al. 2012) or by identifying differences in the trait expression of benthic communities between contrasting environmental settings (Bolam et al. 2017). Studies have also used established proxies to assess the spatial variability in single ecosystem functions such as secondary production (Bolam and Eggleton 2014) or bioturbation (Gogina et al. 2017). Interestingly, hot spots for ecosystem functionality have also been identified by encompassing a range of ecosystem processes in several habitats (Eyre and Maher 2011). By quantifying each individual ecosystem process, using measured process rates and area extent of the habitat, the functional importance of each habitat to overall ecosystem multifunctionality was estimated (Eyre and Maher 2011). Furthermore, where data are scarce, the potential for multiple ecosystem services has been mapped through defining them from a series of principles based on current ecological understanding and by linking these to marine biophysical parameters (Townsend et al. 2014). Utilizing a spatially large data set, as well as expert knowledge, our study takes the above mentioned approaches a step forward by offering a template on how to identify and score relevant functional trait subgroupings for estimating a range of ecosystem properties, resulting in an overall approximation of ecosystem multifunctionality.

In this study, we used groupings of biological traits as a proxy for benthic ecosystem properties. By starting from a species by traits matrix with abundance-corrected, fuzzy coded data, we recognize that species' affinities to different trait modalities do vary. Interestingly, despite the large number of possible combinations among trait modalities for each process, our study identifies that traits do not occur randomly and that only a smaller number of combinations are realized, simplifying the assignation of species to trait subgroups that represent ecosystem properties. Such trait interactions can be a result of trade-offs (i.e., the investment in one trait modality leaves fewer resources available for another), spin offs (selection favors traits modalities that act together), or a result of constraints (Verberk et al. 2013). For example, we found that a semelparous reproductive frequency often favored direct development of juveniles. This trade-off increases the survival probability for the juveniles at the expense of adult survival (Giangrande et al. 1994). As predicted by the rate of living theory, we also observed that larger animals had a longer life span than smaller species, which could be considered as a spin-off directed by metabolic rate (Brown et al. 2004). When describing the benthic bioturbation potential, a constrained interaction is exemplified 
by the epibenthic fauna, which mainly modified the sediment surface (cf. Pearson 2001).

However, another explanation for the small number of trait interactions observed could be the reduced species diversity occurring in the Baltic Sea. The current distribution of species in the Baltic Sea is a result of strong environmental filtering (Bonsdorff 2006), implying that species present are adapted to a few environmental niches and likely to present a similar combination of traits. For example, the variation in benthic community structure in our examined study area has been suggested to be a result of similar responses of species' to an underlying environmental gradient across sites (Valanko et al. 2015). How trait modalities interact is an important avenue for new research. It would improve our understanding of species-environment relationship (Poff 1997), and be fundamental for estimating effects of species on ecosystem properties. Convergent evolution in response to environmental features is one of the strongest arguments for categorization of traits (Winemiller et al. 2015). This makes the geologically young Baltic Sea an ideal setting to evaluate trait interactions.

One essential finding of this study is that the identified trait sub-groups differ in functionality compared to the use of single traits. It is clear that consideration of single trait modalities does not describe the functionality of the ecosystem. For example, consider the modality "large" and its importance for benthic bioturbation. Bivalves such as Macoma balthica and Mytilus trossulus can both be "large," but only Macoma affects benthic bioturbation (as Mytilus is an epibenthic species). Our study makes use of mechanisms demonstrated from the literature to derive weighting that estimate the impact of a trait subgroup on a property, acknowledging that certain functional groups are more important for sustaining benthic ecosystem functionality than others (cf. Foley et al. 2010, Norkko et al. 2013, Lohrer et al. 2015). For example, large gallery and biodiffusers in deeper parts of the sediment are known to oxygenate the sediment, which stimulates microbial activity and can enhance overall nutrient binding $\left(\mathrm{PO}_{4}{ }^{3-}\right)$ and/or removal $\left(\mathrm{N}_{2}\right.$; Kristensen 2000). These trait subgroups were thus considered to have a higher impact on sediment bioturbation than, for example, small epibenthic surface modifiers, known to mainly bioturbate and resuspend the top centimeter of the sediment (Orvain et al. 2004).

By using trait groupings to estimate benthic ecosystem properties, we found pronounced divergences between outer, exposed archipelago areas and the innermost sheltered sites. In the outer archipelago areas, benthic fauna generally displayed higher functional diversity and also expressed a greater cumulative expression for bioturbation, stability, and juvenile dispersal. In general, these more exposed outer areas had a higher salinity and coarser sediments than the inner sites. Their fauna was diverse and abundant, and their ecological status (based on the Brackish Water Benthic Index; Perus et al. 2007) has been found to be higher compared to the inner archipelago sites (Snickars et al. 2016). The similarity in spatial patterns observed for the cumulative expression of the three properties suggests that no trade-offs between the considered properties existed (de Bello et al. 2010, Lefcheck et al. 2015). For example, large biodiffusers deep in the sediment had high potential for dispersion (breeding every year and having a long planktotrophic larval stage) and were considered to increase the stability of the benthic community (long life span). Such synergies between ecosystem properties can enable the identification of functionally important areas, serving as "hotspots" also from biodiversity and marine spatial planning perspective (cf. Foley et al. 2010, Lavorel et al. 2011) and highlight the importance of a few, abundant, key species for overall ecosystem functioning (cf. Norkko et al. 2013). Considering their disproportionate impact, it is suggested that ecosystem-based marine spatial planning efforts should aim to preserve and, if necessary, restore such populations of functionally important species (Foley et al. 2010).

Interestingly, however, due to high abundance of one functionally important taxon, Marenzelleria spp., basins could express high multifunctionality although having only a moderate diversity (in terms of species and trait combinations). Marenzelleria spp. is an invasive surface deposit feeder and an efficient bioirrigator that buries deeper into the sediment than other resident species (Renz and Forster 2013) and adds new functionality to the native communities (Hewitt et al. 2016, Kauupi et al. 2017). This species is known to be tolerant against disturbances and can endure low oxygen conditions (Norkko et al. 2012), indicating that conditions at a site do not have to be good for all species in order to exhibit high levels of multifunctionality.

Although high diversity might not be a requirement for the maintenance of benthic ecosystem functions even in low-diverse systems such as the Baltic Sea (Elmgren and Hill 1997), preserving or restoring species and functional diversity will be essential for sustaining ecosystem services from a management point of view (Foley et al. 2010, Greenfield et al. 2016). This is especially important in cases where the loss or reduction of individual species can lead to the loss of an entire functional group, with harmful consequences for benthic ecosystem functions (Elmgren and Hill 1997, Norkko et al. 2013, Greenfield et al. 2016). Indeed, our results showed that the inner water basins, characterized by a low potential for the examined ecosystem properties, had benthic communities expressing fewer and less influential trait groupings for benthic bioturbation, stability, and dispersal. Still, a majority of the considered water basins could not be separated according to differences in functional trait subgroups, and the variability in the estimations of ecosystem properties within water basins was generally high. Between 32 and $47 \%$ of the variation in single ecosystem properties could be explained by environmental factors. Interestingly, the overall estimate of benthic ecosystem multifunctionality gained the highest explanatory power $(62 \%)$ and was foremost directed by variation in sediment organic 
content. It is important to highlight that the variation in benthic properties and ecosystem multifunctionality can be explained by environmental variables indicative of eutrophication-induced hypoxia, the most prominent disturbance of benthic habitats in the Baltic Sea (Conley et al. 2011). It suggests that this template could be used to evaluate what benthic ecosystem functions might be lost in case of stress (Mouillot et al. 2013) and provides managers with a method to assess human impact, which is essential for resource planning and ecosystem based management (Townsend et al. 2014).

The suggested template for estimating properties of the benthic ecosystem and combining these to a measure of multifunctionality is an approach driven by expert opinion as well as large-scale data. In addition to the literature-based weighting of the impact of the sub-groups on each property, the subsequent calculation of multifunctionality of the benthic ecosystem relies on a subjective definition of percentile thresholds and associated scores for each property. The validity of this method depends on the size of the underlying data set, and therefore we suggest that in case of small data sets, bias-corrected bootstrapping of the samples could be used before identifying the percentiles. By relying on expert opinion, it should be stressed that the suggested template does not offer a quantitative estimation of benthic ecosystem functions. It is a "best you can get" approach, where uncertainties depend on available knowledge of species and their traits, and the inherent differences in species' trait expression. Hence, the template simply offers an identification of sites with higher and lower potential for benthic ecosystem properties and multifunctionality.

The advantages of the suggested template is that different properties of the ecosystem can be assessed, if only trait data are available. For example, the approach can be used to estimate the provision of food resources by the benthic ecosystem to higher trophic levels by accounting for traits such as energy content and palatability (Weigel et al. 2016). The template can also be replicated to other data sets and give an estimate of, for example, biodiversity as predicted by traits describing benthic habitat complexity across scales (Thrush et al. 2001). Hereby, the approach could offer a way to assess the ecological impacts of trawling and dredging. By using the template it is also possible to account for across habitat and ecosystem functionality, through evaluating the contribution of different compartments to common properties. For example, by quantifying traits such as carbon content and turn-over in both algae, vascular plants and animals, estimations on current carbon stocks and their stability and maintenance could be performed in ecosystems facing global change. The trait grouping approach could be a useful and relatively simple way of extracting information that bears relevance to assessments of ecosystem functionality, including pinpointing areas with different levels of functional capacity. This is central for successful conservation efforts and for identification of areas in need of mitigation measures.

\section{ACKNOWLedgments}

We thank Anna Arnkil for help in field and laboratory. The laboratory work in 2012 was financed by Uusimaa ELY-centre as part of the VELMU programme. We wish to especially thank Tero Taponen at Uusimaa ELY-centre. We are grateful to Sebastian Valanko and Laura Kauppi that collected the subset of environmental data, and to Tvärminne Zoological Station for providing excellent research facilities. The manuscript was significantly improved by comments of two anonymous reviewers, which is gratefully acknowledged. This study was funded by the Maj and Tor Nessling Foundation (Grant no. 2014322), the Sophie von Julins Stiftelse and the BONUS COCOA and BalticApp projects, which was supported by BONUS (Art 185), funded jointly by EU and the Academy of Finland.

\section{Literature Cited}

Anderson, M. J., R. N. Gorley, and K. R. Clarke. 2008. PERMANOVA+ for PRIMER: Guide to software and statistical methods. PRIMER-E, Plymouth, UK.

Anselin, L. 1995. Local indicators of spatial association-LISA. Geographical Analysis 27:93-115.

Bekkby, T., P. E. Isachsen, M. Isæus, and V. Bakkestuen. 2008. GIS modeling of wave exposure at the seabed: a depthattenuated wave exposure model. Marine Geodesy 31:117-127.

Belley, R., and P. V. R. Snelgrove. 2016. Relative contributions of biodiversity and environment to benthic ecosystem functioning. Frontiers in Marine Science 3:242. doi: 10.3389/ fmars.2016.00242

Benjamini, Y., and Y. Hochberg. 1995. Controlling the false discovery rate: a practical and powerful approach to multiple testing. Journal of the Royal Statistical Society Series B 57: 289-300.

Böhnke-Henrichs, A., C. Baulcomb, R. Koss, S. S. Hussain, and R. S. de Groot. 2013. Typology and indicators of ecosystem services for marine spatial planning and management. Journal of Environmental Management 130:135-145.

Bolam, S. G., and J. D. Eggleton. 2014. Macrofaunal production and biological traits: spatial relationships along the UK continental shelf. Journal of Sea Research 64:166-179.

Bolam, S. G., et al. 2017. Differences in biological traits composition of benthic assemblages between unimpacted habitats. Marine Environmental Research. https://doi.org/ 10.1016/j.marenvres.2017.01.004

Bonsdorff, E. 2006. Zoobenthic diversity-gradients in the Baltic Sea: continuous post-glacial succession in a stressed ecosystem. Journal of Experimental Marine Biology and Ecology 330:283-291.

Bonsdorff, E., and T. H. Pearson. 1999. Variation in the sublittoral macrozoobenthos of the Baltic Sea along environmental gradients: a functional group approach. Australian Journal of Ecology 24:312-326.

Bremner, J., S. I. Rogers, and C. L. J. Frid. 2003. Assessing functional diversity in marine benthic ecosystems: a comparison of approaches. Marine Ecology Progress Series 254:11-25.

Bremner, J., R. Si, and C. L. J. Frid. 2006. Matching biological traits to environmental conditions in marine benthic ecosystems. Journal of Marine Systems 60:302-316.

Brown, J. H., J. F. Gillooly, A. P. Allen, V. M. Savage, and G. B. West. 2004. Toward a metabolic theory of ecology. Ecology 85:1771-1789.

Chevenet, F., S. Dolédec, and D. Chessel. 1994. A fuzzy coding approach for the analysis of long-term ecological data. Freshwater Biology 31:295-309.

Clarke, K. R., R. N. Gorley, P. J. Somerfield, and R. M. Warwick. 2014. Change in marine communities: an approach 
to statistical analysis and interpretation. Third edition. PRIMER-E, Plymouth, UK.

Clarke, K. R., and R. N. Gorley. 2015. PRIMER v7: User manual/tutorial. PRIMER-E, Plymouth, UK.

Conley, D. J., et al. 2011. Hypoxia is increasing in the coastal zone of the Baltic Sea. Environmental Science and Technology 45:6777-6783.

de Bello, F., et al. 2010. Towards an assessment of multiple ecosystem processes and services via functional traits. Biodiversity and Conservation 19:2873-2893.

Elmgren, R., and C. Hill. 1997. Ecosystem function at low biodiversity - the Baltic example. Pages 319-336 in R. F. G. Ormond, J. Gage, and M. Angel, editors. Marine biodiversity: patterns and processes. Cambridge University Press, Cambridge, UK.

Emmerson, M. C., and D. Raffaelli. 2004. Predator-prey body size, interaction strength and the stability of a real food web. Journal of Animal Ecology 73:399-409.

Eyre, B. D., and D. Maher. 2011. Mapping ecosystem processes and function across shallow seascapes. Continental Shelf Research 31:S162-S172.

Fauchald, K., and P. A. Jumars. 1979. The diet of worms: a study of polychaete feeding guilds. Oceanography and Marine Biology: An Annual Review 17:193-284.

Fish, J. D., and S. Fish. 1996. A student's guide to the seashore. Second edition. Cambridge University Press, Cambridge, UK.

Foley, M. M., et al. 2010. Guiding ecological principles for marine spatial planning. Marine Policy 34:955-966.

Giangrande, A., S. Geraci, and G. Belmonte. 1994. Life-cycle and life-history diversity in marine invertebrates and the implications in community dynamics. Oceanography and Marine Biology: An Annual Review 32:305-333.

Gogina, M., C. Morys, S. Forster, U. Gräwe, R. Friedland, and M. Zettler. 2017. Towards benthic ecosystem functioning maps: Quantifying bioturbation potential in the German part of the Baltic Sea. Ecological Indicators 73:574-588.

Greenfield, B. L., C. Kraan, C. Pilditch, and S. F. Thrush. 2016. Mapping functional groups can provide insight into ecosystem functioning and potential resilience of intertidal sandflats. Marine Ecology Progress Series 548:1-10.

Griffiths, J. R., et al. 2017. The importance of benthic-pelagic coupling for marine ecosystem functioning in a changing world. Global Change Biology 23:2179-2196.

Halpern, B. S., et al. 2008. A global map of human impact on marine ecosystems. Science 319:948-952.

Harris, R. J., C. A. Pilditch, J. E. Hewitt, A. M. Lohrer, C. Van Colen, M. Townsend, and S. F. Thrush. 2015. Biotic interactions influence sediment erodibility on wave-exposed sandflats. Marine Ecology Progress Series 523:15-30.

Haukioja, E., and T. Hakala. 1978. Life-history evolution in Anodonta piscinalis (Mollusca, Pelecypoda). Oecologia 35: 253-266.

Hewitt, J. E., S. F. Thrush, and P. D. Dayton. 2008. Habitat variation, species diversity and ecological functioning in a marine system. Journal of Experimental Marine Biology and Ecology 366:116-122.

Hewitt, J. E., J. Norkko, L. Kauppi, A. Villnäs, and A. Norkko. 2016. Species and functional trait turnover in response to broad-scale change and an invasive species. Ecosphere 7: e01289.

Hooper, D. U., et al. 2005. Effects of biodiversity on ecosystem functioning; a consensus of current knowledge. Ecological Monographs 75:3-35.

Karonen, M., A. Mäntykoski, V. Lankiniemi, E. Nylander, and K. Lehto. 2015. Vesien tila hyväksi yhdessä. Ehdotus
Kymijoen-Suomenlahden vesienhoitoalueen vesienhoitosuunnitelmaksi vuosiksi 2016-2021. Juvenes Print, Tampere, Finland.

Kauppi, L., J. Norkko, J. Ikonen, and A. Norkko. 2017. Seasonal variability in ecosystem functions: quantifying the contribution of invasive species to nutrient cycling in coastal ecosystems. Marine Ecology Progress Series 572:193-207.

Kristensen, E. 2000. Organic matter diagenesis at the oxic/ anoxic interface in coastal marine sediments, with the emphasis on the role of burrowing animals. Hydrobiologia 426:1-24.

Kristensen, E., M. Delefosse, C. O. Quintana, M. R. Flindt, and T. Valdemarsen. 2014. Influence of benthic macrofauna community shifts on ecosystem functioning in shallow estuaries. Frontiers in Marine Science 41:1-14.

Lavorel, S., K. Grigulis, P. Lamarque, M.-P. Colace, D. Garden, J. Girel, G. Pellet, and R. Douzet. 2011. Using plant functional traits to understand the landscape distribution of multiple ecosystem services. Journal of Ecology 99:135-147.

Lefcheck, J. S., J. E. K. Byrnes, F. Isbell, L. Gamfeldt, J. N. Griffin, N. Eisenhauer, M. J. S. Hensel, A. Hector, B. J. Cardinale, and E. Duffy. 2015. Biodiversity enhances ecosystem multifunctionality across trophic levels and habitats. Nature Communications 6:6936. https://doi.org/10.1038/ ncomms 7936

Lohrer, A. M., S. F. Thrush, J. E. Hewitt, and C. Kraan. 2015. The up-scaling of ecosystem functions in a heterogeneous world. Scientific Reports 5:10349. https://doi.org/10.1038./srep10349

Lotze, H. K., H. S. Lenihan, B. J. Bourque, R. H. Bradbury, R. G. Cooke, M. C. Kay, S. M. Kidwell, M. X. Kirby, C. H. Peterson, and J. B. C. Jackson. 2006. Depletion, degradation and recovery potential of estuaries and coastal seas. Science 312:1806-1809.

MarLIN. 2006. BIOTIC-biological traits information catalogue. Marine Life Information Network, Marine Biological Association of the United Kingdom, Plymouth, UK. www.marlin.ac.uk/biotic

Mouillot, D., N. A. J. Graham, S. Villéger, N. W. H. Mason, and D. R. Bellwood. 2013. A functional approach reveals community responses to disturbances. Trends in Ecology and Evolution 28:167-177.

Norkko, A., J. E. Hewitt, S. F. Thrush, and G. A. Funnell. 2006. Conditional outcomes of facilitation by a habitat-modifying subtidal bivalve. Ecology 87:226-234.

Norkko, J., D. C. Reed, K. Timmerman, A. Norkko, B. G. Gustafsson, E. Bonsdorff, C. P. Slomp, J. Carstensen, and D. J. Conley. 2012. A welcome can of worms? Hypoxia mitigation by an invasive species. Global Change Biology 18:422-434.

Norkko, A., A. Villnäs, J. Norkko, S. Valanko, and C. Pilditch. 2013. Size matters: implications of the loss of large individuals for ecosystem function. Scientific Reports 3:2646. https://doi.org/10.1038/srep02646

Norkko, J., J. Gammal, J. E. Hewitt, A. B. Josefson, J. Carstensen, and A. Norkko. 2015. Seafloor ecosystem function relationships: In situ patterns of change across gradients of increasing hypoxic stress. Ecosystems 18:1424-1439.

Orvain, F., P.-G. Sauriau, A. Sygut, L. Joassard, and P. Le Hir. 2004. Interacting effects of Hydrobia ulvae bioturbation and microphytobenthos on the erodibility of mudflat sediments. Marine Ecology Progress Series 278:205-223.

Pearson, T. H. 2001. Functional group ecology in soft-sediment marine benthos: the role of bioturbation. Oceanography and Marine Biology: An Annual Review 39:233-267.

Pearson, T. H., and R. Rosenberg. 1978. Macrobenthic succession in relation to organic enrichment and pollution of the marine environment. Oceanography and Marine Biology: An Annual Review 16:229-311. 
Perus, J., E. Bonsdorff, S. Bäck, H.-G. Lax, A. Villnäs, and V. Westberg. 2007. Zoobenthos as indicators of ecological status in coastal brackish waters: a comparative study from the Baltic Sea. Ambio 26:250-256.

Pilditch, C. A., S. Valanko, J. Norkko, and A. Norkko. 2015. Post-settlement dispersal: the neglected link in maintenance of soft-sediment biodiversity. Biology Letters 11:20140795.

Poff, N. L. 1997. Landscape filters and species traits: towards mechanistic understanding and prediction in stream ecology. Journal of the North American Benthological Society 16:391-409.

Queirós, A. M., et al. 2013. A bioturbation classification of European marine infaunal invertebrates. Ecology and Evolution 3:3958-3985.

Rees, S. E., M. C. Austen, M. J. Attrill, and L. D. Rodwell. 2012. Incorporating indirect ecosystem services into marine protected area planning and management. International Journal of Biodiversity Science, Ecosystem Services and Management 8:273-285. https://doi.org/10.1080/21513732.2012.680500

Renz, J. R., and S. Forster. 2013. Are similar worms different? A comparative tracer study on bioturbation in the three sibling species Marenzelleria arctica, M. viridis, and M. neglecta from the Baltic Sea. Limnology and Oceanography 58:2046-2058.

Sirot, C., S. Villéger, D. Mouillot, A. M. Darnaude, J. RamosMiranda, D. Flores-Hernandez, and J. Panfili. 2015. Combinations of biological attributes predict temporal dynamics of fish species in response to environmental changes. Ecological Indicators 48:147-156.

Snelgrove, P. V. R., S. F. Thrush, D. H. Wall, and A. Norkko. 2014. Real world biodiversity-ecosystem functioning: a seafloor perspective. Trends in Ecology and Evolution 29:398-405.

Snickars, M., et al. 2016. Assessment of the status of the zoobenthos in the coastal waters of western Uusimaa, SW Finland-a tool for management. Nature Protection Publications of Metsähallitus Series A 224:55.

Solan, M., B. J. Cardinale, A. L. Downing, K. A. M. Engelhardt, J. L. Ruesink, and D. S. Srivastava. 2004. Extinction and ecosystem function in the marine benthos. Science 306:1177-1180.

Statzner, B., B. Bis, S. Dolédec, and P. Usseglio-Polatera. 2001. Perspectives for biomonitoring at large spatial scales: a unified measure for the functional composition of invertebrate communities in European running waters. Basic and Applied Ecology 2:73-85.

Thrush, S. F., J. E. Hewitt, G. A. Funnell, V. J. Cummings, J. Ellis, D. Schultz, D. Talley, and A. Norkko. 2001. Fishing disturbance and marine biodiversity: the role of habitat structure in simple soft-sediment systems. Marine Ecology Progress Series 223:277-286.

Thrush, S. F., J. E. Hewitt, M. Gibbs, C. Lundquist, and A. Norkko. 2006. Functional role of large organisms in intertidal communities: community effects and ecosystem function. Ecosystems 9:1029-1040.
Tolonen, K. E., L. Tokola, M. Grönroos, J. Hjort, O.-M. Kärnä, J. Erkinaro, and J. Heino. 2016. Hierarchical decomposition of trait patterns of macroinvertebrate communities in subarctic streams. Freshwater Science 35:1032-1048.

Törnroos, A., and E. Bonsdorff. 2012. Developing the multitrait concept for functional diversity: lessons from a system rich in functions but poor in species. Ecological Applications 22: 2221-2236.

Townsend, M., S. F. Thrush, A. M. Lohrer, J. E. Hewitt, C. J. Lundquist, M. Carbines, and M. Felsing. 2014. Overcoming the challenges of data scarcity in mapping marine ecosystem service potential. Ecosystem Services 8:44-55.

Valanko, S., A. Norkko, and J. Norkko. 2010. Strategies of post-larval dispersal in non-tidal soft-sediment communities. Journal of Experimental Marine Biology and Ecology 384: $51-60$.

Valanko, S., J. Heino, M. Westerbom, M. Viitasalo, and A. Norkko. 2015. Complex metacommunity structure for benthic invertebrates in a low-diversity coastal system. Ecology and Evolution 5:5203-5215.

Verberk, W. C. E. P., C. G. E. van Noordwijk, and A. G. Hildrew. 2013. Delivering on a promise: integrating species traits to transform descriptive community ecology into a predictive science. Freshwater Science 32:531-547.

Villnäs, A., and A. Norkko. 2011. Benthic diversity gradients and shifting baselines: implications for assessing environmental status. Ecological Applications 21:2172-2186.

Villnäs, A., J. Perus, and E. Bonsdorff. 2011. Structural and functional shifts in zoobenthos induced by organic enrichment-implications for community recovery potential. Journal of Sea Research 65:8-18.

Villnäs, A., J. Norkko, S. Hietanen, A. B. Josefson, K. Lukkari, and A. Norkko. 2013. The role of recurrent disturbances for ecoystem multifunctionality. Ecology 94:2275-2287.

Violle, C., P. B. Reich, S. W. Pacala, B. J. Enquist, and J. Kattge. 2014. The emergence and promise of functional biogeography. Proceedings of the National Academy of Sciences USA 111:13690-13696.

Vuori, K.-M., et al. 2006. Suomen pintavesien tyyppittelyn ja ekologisen luokittelujärjestelmän perusteet. Suomen ympäristö 807:151.

Weigel, B., T. Blenckner, and E. Bonsdorff. 2016. Maintained functional diversity in benthic communities in spite of diverging functional identities. Oikos 125:1421-1433.

Whitlatch, R. B., A. M. Lohrer, S. F. Thrush, R. D. Pridmore, J. E. Hewitt, V. J. Cummings, and R. N. Zajac. 1998. Scaledependent benthic recolonization dynamics: life stage-based dispersal and demographic consequences. Hydrobiologia 375/ 376:217-226.

Winemiller, K. O., D. B. Fitzgerald, L. M. Bower, and E. R. Pianka. 2015. Functional traits, convergent evolution and periodic tables of niches. Ecology Letters. https://doi.org/10. 1111/ele.12462

\section{SUPPORTING INFORMATION}

Additional supporting information may be found online at: http://onlinelibrary.wiley.com/doi/10.1002/eap.1630/full

Data Availability

Data available from the Dryad Digital Repository: https://doi.org/10.5061/dryad.3v5d2 